\section{DSL-022 SIMPLIFICATION OF ANTIRETROVIRAL TREATMENT WITH DARUNAVIR/RITONAVIR. THE FINANCIAL IMPACT OF MONOTHERAPY}

doi:10.1136/ejhpharm-2013-000276.265

JM Fernandez-Martin, 0 Urquizar-Rodriguez, JA Morales-Molina, P Acosta-Robles, JE Martinez-Plata, MJ Gimeno-Jorda, F Verdejo-Reche, A Martos-Rosa. Hospital Poniente Del Ejido, Pharmacy, El Ejido, Spain

Background Currently, drugs for HIV treatment have an important financial impact in our hospital Pharmacy Department. Protease Inhibitor (PI) monotherapy is a useful tool that can be used for selected patients

Purpose To determine the proportion of patients on antiretroviral therapy (ART) who could benefit from simplification to Darunavir/ Ritonavir (DRV/r) and evaluate its financial impact

Materials and Methods Retrospective study conducted in a primary hospital between September 2011 and September 2012. Patients included were those being treated for HIV infection. Simplification criteria [1] (CS) for DRV/r were the following: patients without a history of failure of Protease Inhibitors (PIs), undetectable viral load ( $\mathrm{VL}<50 \mathrm{c} / \mathrm{mL}$ ) over the last 6 months, adherence to treatment $>95 \%$ and/or intolerance to Nucleoside Reverse Transcriptase Inhibitors (NRTIs). We excluded HIV-2 patients, those coinfected with chronic hepatitis B virus or already treated with PI monotherapy (DRV/r). Clinical data were collected from medical and dispensing records from outpatients.

Results Patients on ART: 346 . Of those, 34 patients met the CS. Their previous ARTs were: 18 with 2 NRTI+ 1 PI, 7 with 2 NRTI + 1 Non-Nucleoside Reverse Transcriptase Inhibitors (NNRTI) and 9 with other ART. The most prevalent NRTIs, PIs and NNRTIs were tenofovir (76\%), lopinavir (38\%) and efavirenz (14\%). There were 14 patients with no response to PIs, 68 with detectable VL, 89 with adherence $<95 \%$ and 69 with intolerance to NRTIs. Average savings per patient/year: $€ 3,246$. Total savings: $€ 110,378$ per year $(4.7 \%$ of the total HIV cost)

Conclusions Almost $10 \%$ of patients treated with HIV drugs could be on simplified treatment. $73 \%$ of previous ARTs were 2 NRTI plus 1 PI or NNRTI, which is consistent with reference clinical studies. Simplifying the treatment could improve adherence and tolerance in patients as well as cost effectiveness in the ambulatory management of these drugs.

Reference

1. EACS Clinical Guidelines, October 2011 (v.6).

No conflict of interest.

\section{DSL-023 THE COST ANALYSIS OF INTRODUCING THE TWO-BIN REPLENISHMENT SYSTEM FOR MEDICAL DEVICES, ANTISEPTICS AND INTRAVENOUS FLUIDS IN A GERIATRIC HOSPITAL}

doi:10.1136/ejhpharm-2013-000276.266

${ }^{1}$ E Lelieur, 'P Goffinet, ${ }^{2} \mathrm{G}$ Simonet, ${ }^{2} \mathrm{~V}$ Chaumard, 'L Derain. 'Hospices Civils de Lyon, Pharmacie Centrale, Saint Genis Laval, France; ${ }^{2}$ Hospices Civils de Lyon, Pierre Garraud, Lyon, France

Background The two-bin replenishment system has been launched in some public hospitals of Lyon for medical devices, antiseptics and intravenous fluids.

Purpose To make a cost analysis of setting up the two-bin system in a hospital that has eleven wards.

Materials and Methods We identified the cost differences between the new two-bin replenishment system and the previous one from the perspective of the hospital.

Self-assessment questionnaires aimed to gather the following information:
- the time spent using the original system and the new one over a period of one week,

- the time spent setting up the new system.

The questionnaires were carried out on the wards, pharmacy and with the staff in charge of the setting up. Then we gave a value to the times collected using the amount charged for salaries in 2011.

The amount of products returned to the pharmacy was used as an indicator of the cost savings between the two systems. We also collected the cost of furniture.

We finally made an amortisation schedule of the collected costs. Results Eight out of the eleven wards answered the self-assessment questionnaire. The value of staff time saved with the two bin replenishment system was found to be $€ 13,800$ per year. The difference in cost between the new and the original stock was around $€ 7600$. We compared these savings with the cost of setting up the new system. It cost $€ 24,500$ in manual labour expenses and $€ 35,600$ for the furniture and renovation works.

The amortisation schedule shows a return on investment in 3 years.

Conclusions This study reinforced our wish to develop this type of replenishment in our other public hospitals as its safety benefit has been published in a previous report (MEAH report - September 2006).

No conflict of interest.

\section{Drug information}

(i. anti-infectives, ii. cytostatics, iii. others)

\section{DGI-001 A SYSTEMATIC REVIEW OF PERCEPTIONS OF EHEALTH AND SHARED CARE}

doi:10.1136/ejhpharm-2013-000276.267

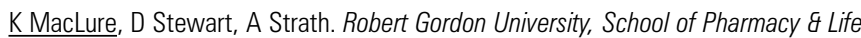
Sciences, Aberdeen, UK

Background The World Health Organization (WHO) defines eHealth as 'the combined use of information and communications technologies for health' [1]. eHealth strategies worldwide aim to promote quality, safety and efficiency by underpinning shared healthcare provision with technology. The Scottish eHealth Strategy incorporates an ePharmacy programme to support pharmacists' increasing role in shared care [2]. It acknowledges organisational development and training for core and optional eHealth services as key.

Purpose To explore and report methodologies, findings and gaps in research related to healthcare professionals' perceptions of the adoption of eHealth technologies for shared care.

Materials and Methods A systematic review was conducted using a meta-narrative approach [3]. Articles published post-2004 in English were included; articles on Internet searches for health information or email were excluded. Data were extracted, synthesised and summarised. Ethical approval was not required.

Results Screening reduced the initial 327 papers identified to 12 which included three reviews, four qualitative, two mixedmethods and three quantitative studies. Data were collected using questionnaires (3), case study (1), group (2) and individual (6) interviews, observation (3) and extraction of data from records (1). Practice settings were remote rural or urban featuring primary care, secondary care or both. The focus was on electronic records (7), telemedicine (2) or general eHealth implementation (3) from the perspective of doctors, nurses, IT developers, policy makers and managers. One study included the views of a hospital pharmacist. Acceptance of eHealth technologies is reported but with cost effectiveness, resourcing and training questioned. Emerging themes are organisational, social and technical. 
Conclusions Strategists worldwide believe technology has the potential to promote quality, safety and efficiency in shared care where organisational, social and technical issues are addressed. However, evidence of hospital pharmacists' views, their perceptions of eHealth and shared care, organisational development and training needs remain under-researched.

\section{References}

1. World Health Organization (2010). Atlas eHealth country profiles: based on the findings of the second global survey on eHealth. WHO Geneva.

2. Scottish Government (2008). eHealth Strategy 2008-2011. Available online at: http://www.scotland.gov.uk/Publications/2008/08 /27103130/13

3. Greenhalgh, T. et al, (2005). Storylines of research in diffusion of innovation: a meta-narrative approach to systematic review. Social science \& medicine, 61(2), pp. 417-430.

No conflict of interest.

\section{DGI-002 ADRENAL INSUFFICIENCY INDUCED BY A CHINESE HERBAL MEDICINE}

doi:10.1136/ejhpharm-2013-000276.268

${ }^{1} \mathrm{M}$ Kieran, ${ }^{2} \mathrm{C}$ Gavin, ${ }^{2} \mathrm{~L}$ O'Shea, ${ }^{3} \mathrm{~J}$ Brady, ${ }^{1} \mathrm{C}$ Meegan. ${ }^{1}$ Mater Misericordiae University Hospital, Pharmacy Department, Dublin, Ireland (Rep.); ${ }^{2}$ Mater Misericordiae University Hospital, Department of Endocrinology, Dublin, Ireland (Rep.); ${ }^{3}$ Mater Misericordiae University Hospital, Biochemistry Department, Dublin, Ireland (Rep.)

Background Chinese herbal medicines have a history, dating back to 1974, of containing strong prescription drugs [1]. In the United States (US), Food and Drug Authority (FDA) analysis of Chinese herbal preparations has found prednisolone, diazepam, paracetamol, indomethacin and hydrochlorothiazide [1]

During a routine review for type 2 diabetes, a MMUH patient reported new-onset fatigue. In view of the presenting complaint, a Synacthen test and thyroid function tests were performed. The patient's Synacthen test reported positive for adrenal insufficiency, despite an absence of other clinical symptoms. Repeat testing and external analysis confirmed the result.

Potential causes of the positive Synacthen test were investigated. On further questioning the patient admitted to taking a 'vitamintype' tablet, which was a Chinese herbal medicine, Cow's Head Brand, Tung Shueh Pills. It was a suspected that the Tung Shueh Pills may have contained corticosteroids, which suppressed the patient's endogenous corticosteroid production, producing a positive Synacthen test.

Purpose To find out whether Cow's Head Brand, Tung Shueh Pills contained corticosteroids.

Materials and Methods Literature review for reports on Cow's Head Brand, Tung Shueh Pills.

Analysis of Cow's Head Brand, Tung Shueh Pills in collaboration with the Irish Medicines Board (IMB)

Results Cow's Head Brand, Tung Shueh Pills manufactured by the Ta Ang Pharmaceutical Company are included on a FDA list of products that require detention when being imported into the US [1]. There is also a case report of Tung Shueh Pills causing acute interstitial nephritis [2].

Review of the listed ingredients of the Tung Shueh pills did not identify any agents known to suppress endogenous corticosteroid production.

The IMB analysis of the agent reported that the product contained betamethasone, arsenic, lead, cadmium and antimony

The patient is currently receiving oral hydrocortisone, which is being tapered in accordance with Synacthen test results.

Conclusions Cow's Head Brand, Tung Shueh pills were found to contain a corticosteroid and heavy metals. Regular administration resulted in suppression of endogenous corticosteroid production, producing drug-induced adrenal insufficiency in a patient.
This case report highlights the importance of including herbal medicines in patients' medicines histories. It also highlights that a lack of regulation of Chinese Herbal Medicines enables inclusion of prescription agents, not included in the product ingredients, which may have significant pharmacological effects on patients.

\section{References}

1. FDA Import Alert \#66-10, issued 18th March 2011. http://www accessdata.fda.gov/cms ia/importalert 173.html

2. Diamond, JR, Pallone, TLL. (1994). Acute interstitial nephritis following use of Tung Shueh Pills. Am J Kidney Disease 24(2), 219-221.

No conflict of interest.

\section{DGI-003 ANALYSIS OF CLINICAL EFFECTIVENESS OF TREATMENT WITH PEGINTERFERON PLUS RIBAVIRIN IN CHRONIC HEPATITIS C MONO-INFECTED PATIENTS}

doi:10.1136/ejhpharm-2013-000276.269

I Larrodé, H Navarro, R Huarte, A Escolano, 0 Pascual, P Casajús, R Abad. Servet, Pharmacy, Zaragoza, Spain

Background Pegylated interferon (Peg-INF) in combination with ribavirin (RBV) is currently the gold standard treatment in chronic hepatitis $\mathrm{C}(\mathrm{HCV})$ patients, achieving viral eradication in approximately $50-60 \%$ of patients in published data.

Purpose To assess the clinical effectiveness of Peg-INF plus RBV for the treatment of chronic HCV mono-infected patients.

Materials and Methods Retrospective observational study involving 152 patients treated from October 2006 to July 2010. We collected demographic data (age, gender), laboratory reports (genotype, viral load), clinical characteristics, type of Peg-INF and RBV and Peg-INF doses. The primary end point was a sustained virological response (SVR). Secondary end points included rapid virological response (RVR), early virological response (EVR) (complete or partial), final viral response (FVR) and virological relapse. Exclusion criteria were: coinfection, haemodialysis and patients with insufficient data to analyse. Data were obtained from the pharmacy database and medical records.

Results 152 patients (mean age 46 years) were analysed and 84 were included. $65.5 \%$ were male. $67.1 \%$ with genotype $1-4.51 .2 \%$ were treated with Peg-INF $\alpha-2 \mathrm{a}$. The average viral load was $1.9 \times 1010 \mathrm{IU} / \mathrm{ml}$ and $40 \%$ of the patients had more than 600,000 $\mathrm{IU} / \mathrm{ml} \mathrm{HCV} \mathrm{RNA.} \mathrm{The} \mathrm{METAVIR} \mathrm{liver} \mathrm{fibrosis} \mathrm{stage} \mathrm{was} \mathrm{F3-F4} \mathrm{in}$ $36.6 \%$ of patients. $62.5 \%(50 / 80)$ achieved SVR, $72.0 \%$ in those with genotype $2-3$ and $60.8 \%$ in $1-4$. RVR was achieved in $31.7 \%$ of patients with genotype $1-4$, and $73.9 \%$ in genotype $2-3.69 .2 \%$ of patients with genotype 1-4 achieved a complete EVR versus $92.3 \%$ in $2-3.11 .5 \%$ of patients with genotype $1-4$ and $7.7 \%$ of those with 2-3 achieved a partial EVR. Relapse rates (18.2\%) were lower in genotype $2-3$ than in $1-4$ ( $75 \%$ of them).

Conclusions The overall SVR rates observed were in accordance with published data, as well as the higher proportion of patients with genotype 2-3 that achieved a RVR and the highest rate of relapse observed in those with genotype $1-4$.

No conflict of interest.

\section{DGI-004 ANALYSIS OF CONSULTATIONS MADE BY PATIENTS IN AN OUTPATIENT SERVICE}

doi:10.1136/ejhpharm-2013-000276.270

I Yeste Gomez, V Escudero Vilaplana, I Marquinez Alonso, C Rodriguez Gonzalez, P Arrabal Duran, B Marzal Alfaro, M Sanjurjo Saez. Hospital General Universitario Gregorio Marañón, Pharmacy, Madrid, Spain

Background hospital pharmacists interview all outpatients with a new prescription, including medication changes, and those who are suspected of not having good compliance. However, patients sometimes voluntarily demand to talk to the pharmacist. 